\title{
Infective Causes of Epilepsy
}

\author{
M. Bonello, MBBS, MRCP ${ }^{1}$ B.D. Michael, MBChB, MRCP, $\mathrm{PhD}^{1,2} \quad$ T. Solomon, MBBS, FRCP, PhD, DTM\&H $\mathrm{H}^{1,2}$ \\ 1 The Walton Centre NHS Foundation Trust, Liverpool, United Kingdom \\ 2 The Institute of Infection and Global Health, University of Liverpool, \\ Liverpool, United Kingdom \\ Address for correspondence B.D. Michael, The Institute of Infection \\ and Global Health, University of Liverpool, 1st Floor Ronald Ross \\ Building, 8 West Derby Street, Liverpool L69 7BE, United Kingdom \\ (e-mail: benedict.michael@liverpool.ac.uk). \\ Semin Neurol 2015;35:235-244.
}

\begin{abstract}
Keywords

- infection

- encephalitis

- epilepsy
\end{abstract}

\section{Infectious Agents Causing Epilepsy}

Any infection of the cortex can potentially result in seizures. This primarily relies upon the structural damage occurring during the infection, although secondary inflammatory processes may also provoke seizures. Certain conditions, including viral encephalitis and parasitic infections-such as "cerebral" malaria and neurocysticercosis-are inherently associated with seizures and the risk of developing epilepsy. Other conditions, such as bacterial meningitis, can cause seizures in the acute setting, although this is less frequent and they rarely result in long-term epilepsy. Here we will review the most common central nervous system (CNS) infectious disorders causing epilepsy, specifically focusing on viral encephalitis and parasitic infections.

\section{Viral Encephalitis}

Encephalitis encompasses a broad range of pathophysiological process that result in inflammation of brain parenchyma and therefore the diagnosis is fundamentally a histopathological one. ${ }^{1,2}$ In view of the impracticality of obtaining brain tissue, surrogate markers of brain inflammation are routinely used to make the diagnosis. These include elevated cerebrospinal fluid (CSF) leukocyte counts, raised protein, evidence of viral nucleic acid in the CSF by polymerase chain reaction (PCR), or intrathecal synthesis of antiviral antibody. Neuroimaging can also help (-Fig. 1)., ${ }^{1,2}$ Encephalitis usually presents with an encephalopathy syndrome for which there is often a broad differential diagnosis. ${ }^{3}$ Features raising suspicion for infective encephalitis include a history of fever or coryzal illness, recent travel, and inadequate vaccination. ${ }^{1}$ A wide range of pathogens can cause encephalitis. Antibodyassociated encephalitis, which may be paraneoplastic or de novo, is of increasingly recognized importance, but it is beyond the scope of this article and is covered elsewhere in this themed edition.

Encephalitis results in roughly 19,000 hospitalizations and 1,400 deaths per year in the United States ${ }^{4}$ with a reported incidence between 0.7 to 13.8 per 100,000 per year. ${ }^{1,3,5}$ It is an important condition as delays in diagnosis and in starting treatment can result in significant morbidity and mortality. Acute symptomatic seizures occur in 2 to $67 \%$ of patients with a diagnosis of encephalitis overall. ${ }^{4}$ The incidence of acute symptomatic seizures and the subsequent development of
Issue Theme Etiology of Epilepsy; Guest Editors: Philip Smith, MD, FRCP,

FAcadMEd, and Rhys Thomas, BSc, MRCP, MSc, PhD
Copyright $\odot 2015$ by Thieme Medical Publishers, Inc., 333 Seventh Avenue, New York, NY 10001, USA. Tel: +1(212) 584-4662.
DOI http://dx.doi.org/ 10.1055/s-0035-1552619. ISSN 0271-8235. 


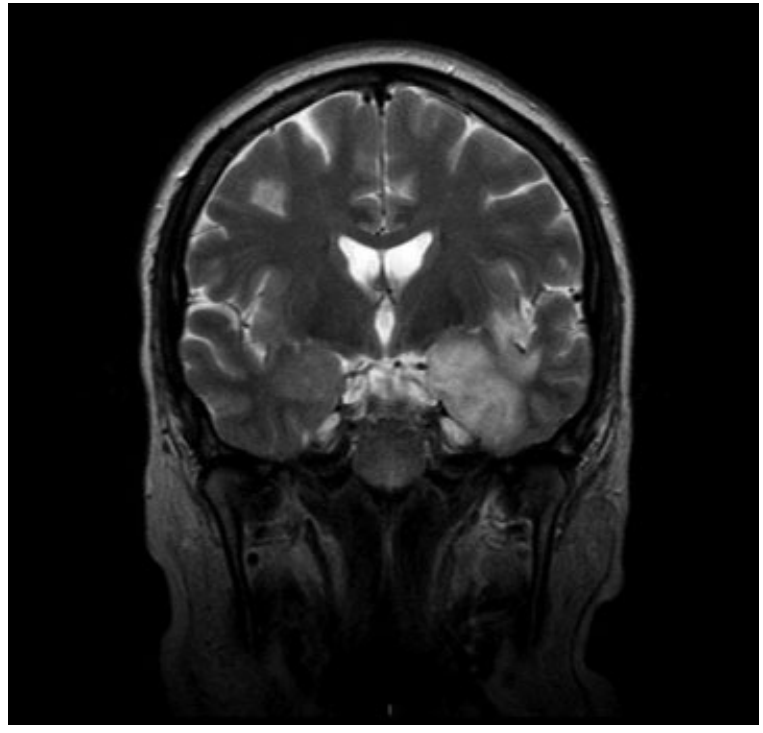

Fig. 1 Magnetic resonance image of brain (coronal T2-weighted) showing typical temporal lobe changes in confirmed herpes simplex virus type 1 (HSV1) encephalitis.

epilepsy vary with the cause of encephalitis, the patient's comorbidities, delays in starting treatment, and the degree of cortical inflammation. ${ }^{6}$ Epidemiological studies of seizures and the long-term outcome for encephalitis are limited and available data are mainly from passive surveillance; therefore, they are prone to underestimate, particularly in resourcepoor settings.

Patients with encephalitis risk developing seizures in the acute setting, but are also more likely to develop later unprovoked seizures as described by the International League Against Epilepsy (ILAE). ${ }^{7}$ Overall, patients with encephalitis are around 16 times more likely than the general population to develop epilepsy. ${ }^{4}$ Of those who have seizures during the acute encephalitic illness, the risk is higher at a 22 times more likely. Even those who do not suffer from acute symptomatic seizures during the acute viral encephalitis are 10 times more likely to develop later unprovoked seizures. The annual incidence of epilepsy due to encephalitis in the United States is approximately the same as that due to head injuries, even though there are 1.4 million cases of CNS trauma per year, compared with fewer than 50,000 cases of CNS infection. ${ }^{4}$

Most commonly, seizures develop within the first 5 years of the acute encephalitic illness, but they may occur up to 20 years after the acute event. The pathogen may be important in determining whether a person subsequently develops epilepsy in the long term. For example, encephalitis caused by La Crosse virus has a cumulative incidence of epilepsy of 10 to $12 \%$ while Nipah virus encephalitis has an incidence of approximately $2.2 \%{ }^{4}$

\section{Causes of Infectious Encephalitis}

Acute infections causing encephalitis group broadly into those occurring either sporadically or epidemically. The most common sporadic cause is herpes simplex virus, usually type 1 , although $10 \%$ are type $2 .^{1}$ Others include varicella zoster virus and enteroviruses. Epidemic encephalitis most commonly occurs in geographically restricted seasonal epidemics and is caused by arthropod-borne viruses (arboviruses), although clinicians need to be vigilant to the potential for advances in the geographical distribution of these pathogens. Globally, the most important epidemic cause is Japanese encephalitis virus, while others include West Nile virus, tickborne encephalitis virus and Nipah virus (-Table 1). ${ }^{5}$

\section{Herpes Simplex Virus Encephalitis}

Herpes simplex virus (HSV) encephalitis has an annual incidence of 1 in 250,000 to 500,000 , although this may be an underestimate. ${ }^{8}$ Herpes simplex virus type 1 is an $\alpha$ herpes double-stranded DNA virus with which most people are infected by adulthood. ${ }^{8}$ It is transmitted by droplet spread and crosses the mucous membranes of the naso-oral cavity and then travels by retrograde axonal transport to sensory ganglia, predominantly the trigeminal ganglion. There it achieves latency, but reactivates periodically, traveling by anterograde axonal transport to the cutaneous nerve endings, resulting in spread of the virus, in some cases associated with a localized vesicular eruption, "herpes labialis." Triggers for viral reactivation include stress, local trauma, fever, immunosuppression, menstruation, or hormone imbalance. The mechanisms resulting in latency and reactivation are not fully understood, but toll-like receptors and the type 1 and 2 interferon response probably play a crucial role in initially establishing and subsequently maintaining latency. ${ }^{9}$ Rarely, the virus replicates in the brain, causing encephalitis although it is unclear whether this result from further retrograde axonal transport after reactivation in the trigeminal ganglion, or whether this is due to reactivation of HSV already latent within the brain (-Fig. 2).

Herpes simplex virus type 1 encephalitis has a bimodal age distribution, with one-third of cases occurring in young adults and one-half of cases occurring in people older than 50 years. ${ }^{10}$ Seizures occur in approximately $40 \%$ of people with HSV 1 encephalitis during the acute illness and may be the presenting symptom. ${ }^{11}$ The seizures are typically focal, with and without cognitive involvement, reflecting temporal lobe and to a lesser extent frontal lobe infection. Clinical features that typically precede seizures include alterations in cognition, consciousness, personality, or behavior, in the context of an intercurrent or recent febrile illness. ${ }^{3}$ However, approximately $11 \%$ of patients with HSV encephalitis are afebrile on admission. ${ }^{12}$ Associated clinical features include headache, nausea, vomiting, and features suggesting meningism and raised intracranial pressure. ${ }^{12}$ The presence of acute symptomatic seizures was associated with a worse outcome in a series of patients with HSV encephalitis; furthermore, the development of status epilepticus is associated with a worse outcome in encephalitis more broadly. ${ }^{4,13}$ In addition, a greater impairment in consciousness, older age, and a delay in starting acyclovir treatment of $>48$ hours are each associated with a worse outcome. ${ }^{4}$

Approximately 45 to $60 \%$ of people with HSV encephalitis develop epilepsy later in life., ${ }^{4,8}$ Initial treatment should be with an antiepileptic medication effective for focal-onset 
Table 1 Causes of acute viral encephalitis

\begin{tabular}{|c|c|c|}
\hline Groups & Viruses & Comments \\
\hline \multicolumn{3}{|l|}{ Sporadic causes } \\
\hline \multirow{6}{*}{$\begin{array}{l}\text { Herpes viruses } \\
\text { (Family Herpesviridae) }\end{array}$} & Herpes simplex virus type 1 & Most commonly diagnosed sporadic encephalitis \\
\hline & Herpes simplex virus type 2 & $\begin{array}{l}\text { Causes meningitis in adults; meningoencephalitis } \\
\text { typically occurs in the immunocompromised; } \\
\text { radiculitis }\end{array}$ \\
\hline & Varicella zoster virus & $\begin{array}{l}\text { Postinfective cerebellitis, or acute infective en- } \\
\text { cephalitis or vasculopathy }\end{array}$ \\
\hline & Epstein-Barr virus & Encephalitis in the immunocompromised \\
\hline & Cytomegalovirus & $\begin{array}{l}\text { Encephalitis in the immunocompromised; retinitis, } \\
\text { radiculitis }\end{array}$ \\
\hline & Human herpes viruses 6 and 7 & $\begin{array}{l}\text { Febrile convulsions in children; encephalitis in the } \\
\text { immunocompromised }\end{array}$ \\
\hline \multirow{4}{*}{$\begin{array}{l}\text { Enteroviruses } \\
\text { (Family } \\
\text { Picornaviridae) }\end{array}$} & Enterovirus 70 & $\begin{array}{l}\text { Epidemic hemorrhagic conjunctivitis, with CNS } \\
\text { involvement }\end{array}$ \\
\hline & Enterovirus 71 & $\begin{array}{l}\text { Epidemic hand, foot, and mouth disease, aseptic } \\
\text { meningitis, brainstem encephalitis, myelitis }\end{array}$ \\
\hline & Poliovirus & Myelitis \\
\hline & $\begin{array}{l}\text { Coxsackie viruses, echoviruses, } \\
\text { parechoviruses }\end{array}$ & Aseptic meningitis \\
\hline \multirow{2}{*}{$\begin{array}{l}\text { Paramyxoviruses } \\
\text { (Family } \\
\text { Paramyxoviridae) }\end{array}$} & Measles virus & $\begin{array}{l}\text { Acute postinfective encephalitis, subacute enceph- } \\
\text { alitis, subacute sclerosing panencephalitis }\end{array}$ \\
\hline & Mumps virus & $\begin{array}{l}\text { Parotitis, orchitis, pancreatitis are associated with } \\
\text { meningoencephalitis }\end{array}$ \\
\hline Others (rarer) & $\begin{array}{l}\text { Influenza viruses, adenovirus, parvovirus B19, } \\
\text { lymphocytic choriomeningitis virus, rubella virus }\end{array}$ & \\
\hline \multicolumn{3}{|c|}{ Arthropod-borne and zoonotic viruses ${ }^{a}$} \\
\hline \multirow[t]{4}{*}{$\begin{array}{l}\text { Flaviviruses (Family } \\
\text { Flaviviridae) }\end{array}$} & West Nile virus & $\begin{array}{l}\text { North America, Southern Europe, Middle East, West } \\
\text { and Central Asia associated with flaccid paralysis and } \\
\text { parkinsonian movement disorders }\end{array}$ \\
\hline & Japanese encephalitis virus & $\begin{array}{l}\text { Asia, associated with flaccid paralysis and parkinso- } \\
\text { nian movement disorders }\end{array}$ \\
\hline & Tick-borne encephalitis virus & $\begin{array}{l}\text { Eastern Europe, Former USSR; upper limb flaccid } \\
\text { paralysis }\end{array}$ \\
\hline & Dengue viruses (types 1-4) & $\begin{array}{l}\text { Causes fever, arthralgia, rash and hemorrhagic dis- } \\
\text { ease; occasional CNS disease }\end{array}$ \\
\hline \multirow[t]{2}{*}{$\begin{array}{l}\text { Alphaviruses (Family } \\
\text { Togaviridae) }\end{array}$} & $\begin{array}{l}\text { Western, Eastern and Venezuelan } \\
\text { equine encephalitis viruses }\end{array}$ & $\begin{array}{l}\text { Found in the Americas; associated with human and } \\
\text { equine encephalitis }\end{array}$ \\
\hline & Chikungunya virus & Asia Pacific, Africa \\
\hline Bunya viruses & La Crosse Virus & Encephalitis in America \\
\hline Coltiviruses & Colorado tick fever virus & North America \\
\hline \multirow[t]{2}{*}{ Rhabdoviruses } & Rabies, virus other lyssaviruses & $\begin{array}{l}\text { Non-arthropod-borne zoonotic viruses transmitted } \\
\text { by dogs, cats, bats depending on location }\end{array}$ \\
\hline & Chandipura virus & Transmitted by sand-flies, causing outbreaks in India \\
\hline Henipaviruses & Nipah virus & $\begin{array}{l}\text { Transmitted in feces of fruit bats in Malaysia, } \\
\text { Bangladesh }\end{array}$ \\
\hline
\end{tabular}

Source: Adapted with permissions from Michael BD, Solomon T. Seizures and encephalitis: clinical features, management, and potential pathophysiologic mechanisms. Epilepsia 2012;53(Suppl 4):63-71.

Abbreviations: CNS, central nervous system.

${ }^{a}$ Most are zoonotic with the exception of dengue and chikungunya viruses. Viral causes of chronic encephalitis like JC virus are not included. 


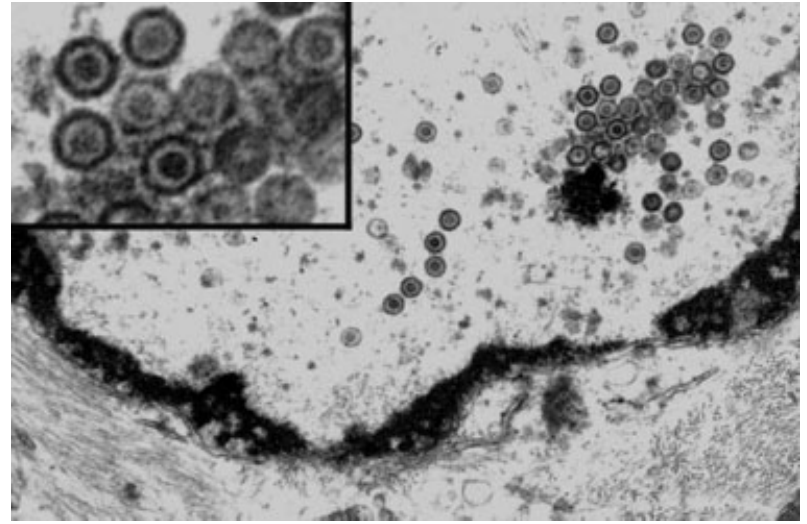

Fig. 2 Electron micrograph image of herpes simplex virus type 1 (HSV1), the most common cause of sporadic encephalitis (http:// library.med.utah.edu/WebPath/jpeg5/CNS176.jpg).

seizures, although these patients frequently require multiple antiepileptic medications. ${ }^{5}$ If a patient has early recurrent seizures, evolving seizure types-particularly with a faciobrachial dystonic semiology-or has associated progressive cognitive decline or neuropsychiatric symptoms, clinicians should consider an early relapse of the encephalitis. This may be due to resurgent viral infection or a postinfective primarily immunomediated process that may be associated with specific antibodies directed against CNS antigens. ${ }^{13}$ Early relapses may develop in up to 10 to $26 \%$ of patients, especially those who received insufficient acyclovir. ${ }^{11}$ However, patients occasionally develop relapses up to 2 years after the initial event. ${ }^{14}$ Therefore, UK guidelines recommend that immunocompetent patients older than 12 years should receive intravenous acyclovir for 14 days, and then undergo a repeat HSV PCR of the CSF. ${ }^{1,2}$ If there is still evidence of HSV infection, they should receive a another 7 days of treatment with further CSF sampling thereafter, and acyclovir continued until the CSF PCR is negative. These guidelines also recommend that a minimum treatment duration of 21 days for immunocompromised patients or those younger than 12 years before repeating CSF sampling. ${ }^{1,2}$

\section{Japanese Encephalitis Virus ${ }^{15}$}

An estimated 70,000 cases of encephalitis due to Japanese encephalitis virus (JEV) occur per year, causing 20,500 deaths. ${ }^{16}$ Although responsible for seasonal epidemics mostly centered around South East Asia, some cases also occur in the Western Pacific and Eastern Mediterranean. ${ }^{17}$ Japanese encephalitis virus is a flavivirus that has a zoonotic transmission with infection between a wide range of vertebrates by Culex mosquitoes, and the predominant cycle is between wading birds, such as egrets, and pigs ( - Fig. 3). Pigs act as amplifying

\section{Enzoonotic transmission of the Japanese encephalitis virus}

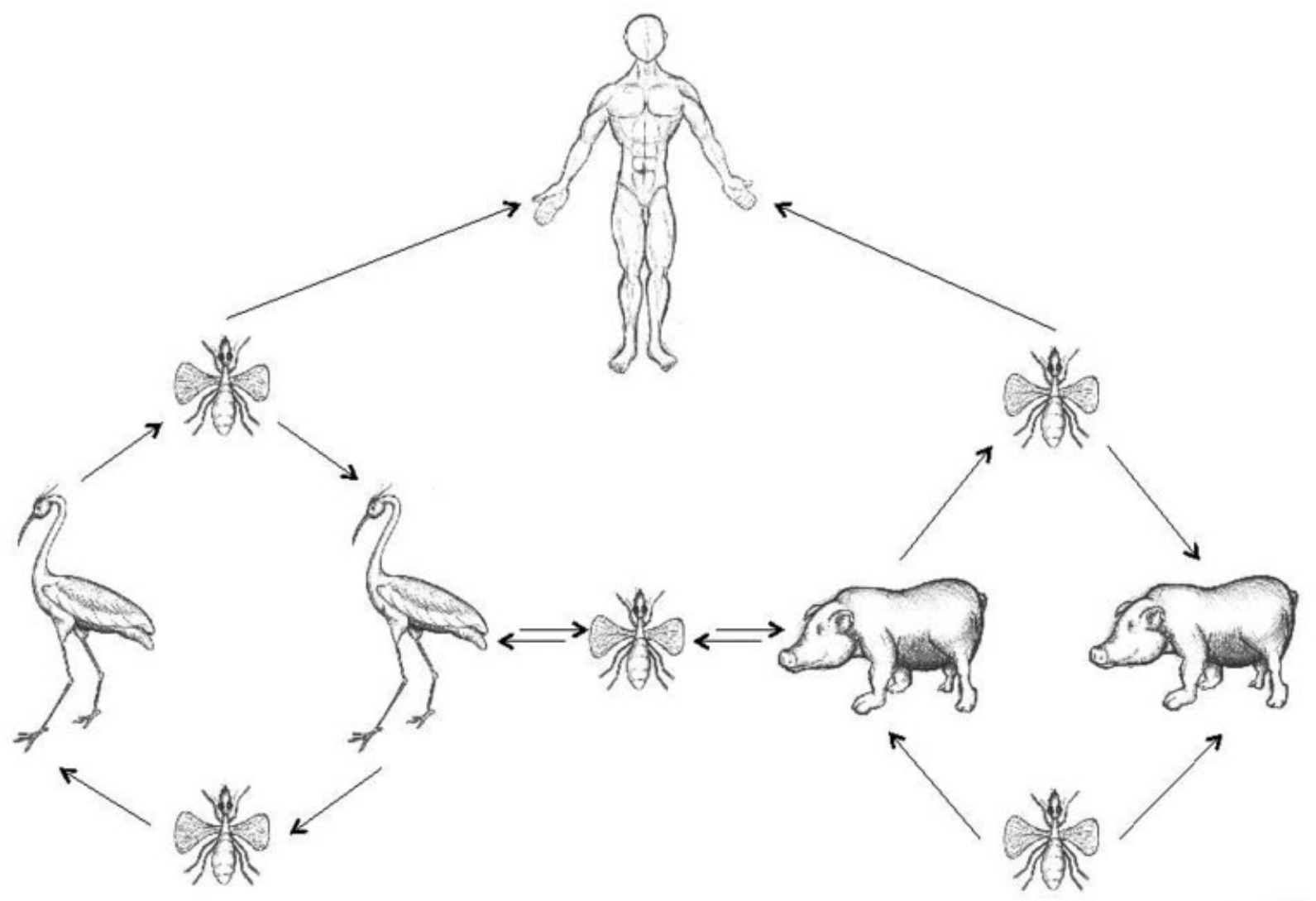

Courtesy of Dr Benedict Mchael

Fig. 3 The enzootic transmission cycle of Japanese encephalitis virus, showing transmission between wading birds (such as egrets) and pigs that act as amplifying hosts. Transmission is mediated by Culex mosquitos and humans are dead-end hosts. 
hosts due to high, prolonged viremia. ${ }^{16}$ This cycle can spill over to humans who are a dead-end host following a mosquito bite. Therefore, the major risk factors for JEV infection are close proximity to rice fields and pigsties. ${ }^{18}$ Acute infection results in a transient, nonspecific febrile viremic illness; in some people, the virus crosses the blood-brain barrier resulting in viral replication in the CNS. This leads to leucocyte transfer into the brain with perivascular cuffing. ${ }^{17}$ Treatment is generally supportive and includes management of the complications such as seizures and raised intracranial pressure. Importantly, Japanese encephalitis is a vaccinepreventable illness; thus, delivering broad and comprehensive vaccination programs is of utmost priority. ${ }^{19}$

Japanese encephalitis virus causes acute symptomatic seizures in up to $85 \%$ of children and in $10 \%$ of adults. ${ }^{20,21}$ Generalized tonic-clonic seizures are more frequent than focal motor seizures; however, the clinical signs may be subtle and seizures can be easily missed, especially if there is limited access to electroencephalography (EEG). In one large cohort study, half of the patients with generalized tonic-clonic seizures and all of those with subtle seizures were in status epilepticus. ${ }^{21}$ Moreover, of patients with confirmed encephalitis due to JEV, those who had acute symptomatic seizures while hospitalized were at least 4 times more likely to have a poor outcome. ${ }^{21}$ Around half of patients who survive the acute illness are left with severe neurologic sequelae, including motor impairment, and cognitive and language dysfunction. ${ }^{22,23}$ Approximately $20 \%$ of survivors are thought to develop long-term seizures, but we need more detailed studies assessing longer-term consequences with a particular focus on late unprovoked seizures and the health economic and social implications. ${ }^{5}$

\section{Role of Human Herpes Virus 6}

The relatively recently identified lymphotropic $\beta$ herpes DNA virus human herpes virus 6 (HHV6) is now realized to be the most common cause of roseola infantum in children aged under 2 years (-Fig. 4). ${ }^{24}$ More broadly, HHV6 may account for $20 \%$ of emergency department admissions for all febrile illnesses in children aged 6 to 12 months, of whom approximately $13 \%$ may develop acute seizures. ${ }^{25}$ In one study of children aged below 5 years presenting with febrile status epilepticus to an emergency department, 32\% had HHV-6B viremia. ${ }^{26}$ HHV6 is found by PCR of the CSF in $10 \%$ of cases of suspected viral CNS disease, regardless of age. ${ }^{27}$ In addition, four studies have reported HHV6 viral DNA in some samples of resected hippocampi from people with mesial temporal lobe sclerosis. HHV6 viral DNA was found in nine (28\%) hippocampal samples that were resected for mesial temporal lobe epilepsy in a Chinese study, but only in one (8\%) of the control patients. ${ }^{28}$ In other studies, there was HHV6 DNA in 15 (62.5\%), 4 (50\%), and 3 (9\%) patients with mesial temporal sclerosis, although there was no control group. ${ }^{29-31}$ This wide variability may reflect patient populations sampled; clearly, we need further work on a larger well-defined cohort with an appropriate control group. In addition, as HHV6 viral DNA can show chromosomal integration, the finding of viral DNA in CSF or brain parenchyma needs confirmation of its

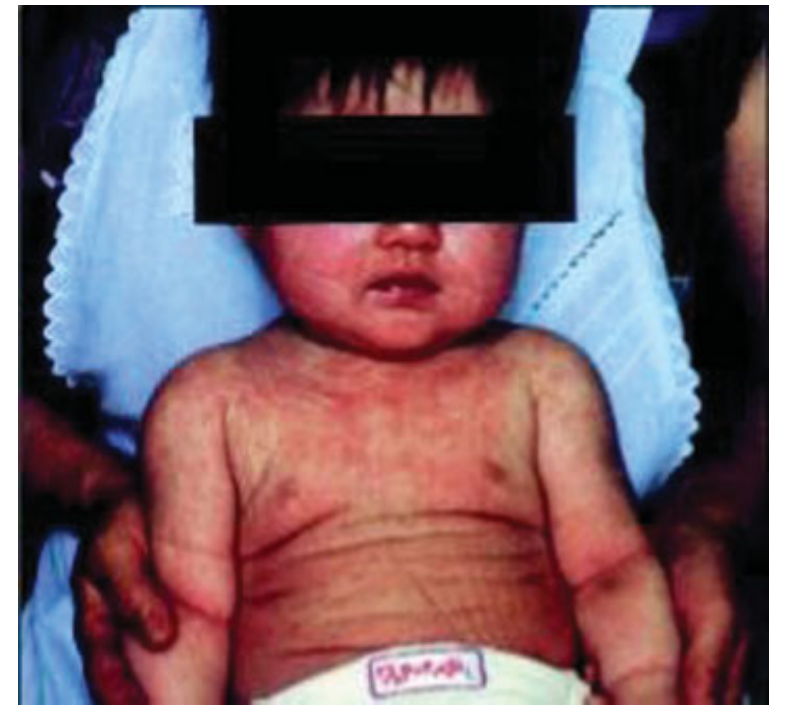

Fig. 4 Typical rash of roseola infantum caused by human herpes virus 6 (HHV6), which is also an important cause of febrile seizures (http:// virology-online.com/viruses/Roseala.jpg).

significance, for example, through establishing a high or rising viral load, an intrathecal antibody response, and excluding chromosomal integration.

\section{Parasitic Infections}

Seizures can complicate parasitic infections of the CNS and may develop both as an acute phase response as well as longterm consequence, although establishing the causality of some organisms can be difficult ( - Table 2 ). ${ }^{32}$ Seizures develop through several mechanisms, including local pressure effects from parasitic growth in the brain parenchyma (e.g., hydatid disease), from inflammation after larval migration, or as part of a diffuse encephalopathy (e.g., African trypanosomiasis). Two major infections associated with a high frequency of seizures and epilepsy are cerebral malaria and neurocysticercosis. ${ }^{30}$

\section{Cerebral Malaria}

There are an estimated 1 million deaths attributed to malaria per year-with half of these resulting from cerebral malariaof whom $90 \%$ are children. ${ }^{33}$ The World Health Organization has defined cerebral malaria as unexplained coma in patients with a parasitemia without any other explanation. ${ }^{34}$ In addition, cerebral malaria may be suspected clinically by a malaria-specific retinopathy, which is $95 \%$ sensitive and $90 \%$ specific for children who are comatose secondary to cerebral malaria. ${ }^{35}$ The epidemiology and clinical phenotype of the condition varies by age and geographical location. Cerebral disease most commonly develops with falciparum malaria and affects mostly African children below the age of 5 years with a rapid onset of coma and focal motor seizures. Adults normally develop cerebral dysfunction in conjunction with dysfunction of other organs.

Up to $30 \%$ of African children have some neurologic sequelae following cerebral malaria; up to $10 \%$ develop 
Table 2 List of parasitic infections associated with seizure disorders ${ }^{56}$

\begin{tabular}{|l|l|}
\hline Type of lesion & Agent \\
\hline Focal granulomatous/cystic lesions & $\begin{array}{l}\text { Protozoa: Toxoplasma, free living amoeba, Chagas disease } \\
\text { Nematodes: Toxocariasis, gnathostoma } \\
\text { Trematodes: Schistosomiasis, paragonimiasis } \\
\text { Cestodes: Cysticercosis, hydatid disease, coenurosis, sparganosis }\end{array}$ \\
\hline Abscess & Entamoeba histolytica, toxoplasmosis \\
\hline Encephalitis & Chagas disease, free-living amoebas, "cerebral malaria" \\
\hline Meningitis & Angiostrongylus, cysticercosis \\
\hline Mass effect & Cysticercosis, hydatid disease, coenurosis \\
\hline
\end{tabular}

epilepsy. ${ }^{36,37}$ The mechanism by which cerebral malaria results in epilepsy is not fully understood, but it probably involves a parasite-driven inflammatory process causing cortical damage, which may predominantly affect the occipital neocortex ${ }^{38}$ and can be confirmed as focal atrophy on neuroimaging months to years later. ${ }^{39}$ However, one case report described hippocampal sclerosis and mesial temporal lobe epilepsy following cerebral malaria. ${ }^{40}$ Clinical seizures are occasionally generalized at onset, but more often are focal with or without subsequent secondary generalization; approximately $20 \%$ of children have subclinical seizures. ${ }^{36}$ Moreover, status epilepticus can occur in up to $28 \%$ of patients and having acute seizures is associated with an increased risk of both mortality and long-term neurologic disability. ${ }^{33,36,41}$

Treatment involves standard antimalarial medication and best supportive care, which may require intensive care input where available. Therefore, clinicians should be vigilant for the potential for seizures in patients with cerebral malaria, and should consider an EEG, where available, to detect subtle motor or nonconvulsive status epilepticus, especially in those with altered and/or fluctuating consciousness. However, even having identified status epilepticus, the optimal treatment regimen is unclear. In one study, neither phenytoin nor fosphenytoin controlled status epilepticus in 36 to $64 \%$ of children with cerebral malaria, despite therapeutic antiepileptic blood concentrations. ${ }^{41}$

\section{Neurocysticercosis}

Neurocysticercosis is the infection of the CNS by the larval stage of the tapeworm Taenia solium, and is the most common helminthic infection of CNS globally. ${ }^{42}$ Taenia solium is endemic in most developing countries and as such is a major public health problem. Millions of people living in the developing world are infected by the larval form of T. solium, and many of these will experience some degree of clinical consequence of the infection. ${ }^{43}$ It is rare in northern Europe, Canada, Australia, Japan, New Zealand, and in many countries with a predominant Muslim population. However, immigration from endemic countries has increased the incidence in these countries more recently. The increasingly widespread use of cysticidal drugs, improved sanitation, and public health educational measures have been associated with a decreasing prevalence of clinical infection. However, neurocysticercosis remains an important cause of hospital admission and a major cause for acquired epilepsy in many areas. ${ }^{44,45}$

The life cycle of $T$. solium involves humans, as the only definite hosts for the adult "cestode," and pigs, which act in conjunction with humans as intermediate hosts for the larval form or cysticercus. The parasite's lifecycle passes through four stages including the vesicular stage, the colloidal stage, the granular stage, and finally the calcified stage (-Fig. 5).

Approximately $80 \%$ of patients with symptomatic neurocysticercosis develop recurrent seizures. Other manifestations include focal neurologic deficits, increased intracranial pressure, and cognitive decline. ${ }^{46}$ Neurocysticercosis is a leading cause of acquired epilepsy in endemic areas and is partly responsible for the increased prevalence of epilepsy in the developing world. These patients probably have focal-onset seizures with rapid generalization. Seizures occur predominantly when the parasites begin to degenerate; calcified lesions have been considered to be inert. However, recent reports suggest that calcified lesion may cause seizures in some people when parasitic antigens trapped in the calcium matrix are exposed to the host immune system during calcification remodeling ( - Fig. 6). ${ }^{47}$ Neurocysticercosis has also been associated with hippocampal sclerosis. ${ }^{48}$ In an appropriate patient with acute symptomatic seizures and exposure to an endemic region, $T$. Solium can be detected on a simple plain radiograph of the quadriceps (-Fig. 7 ).

\section{Management of Seizures}

At the moment, no evidence supports the use of antiepileptic medication as primary prophylaxis in patients with a CNS infection. Indeed, there is limited evidence to guide treatment of seizures that occur during or after the acute CNS infection. ${ }^{1,2,6,49}$ There have been no randomized or quasirandomized controlled trials for the primary or secondary prophylaxis of seizures in viral encephalitis; therefore, there is currently no evidence to support primary prophylaxis, although secondary prevention is routine practice. ${ }^{49}$ A further complicating factor is the management of iatrogenic respiratory failure in the setting of limited resources, as identified in one study of phenobarbital in patients with cerebral malaria. ${ }^{50}$ We need large multicenter randomized controlled trials, but before this, we need risk stratification 


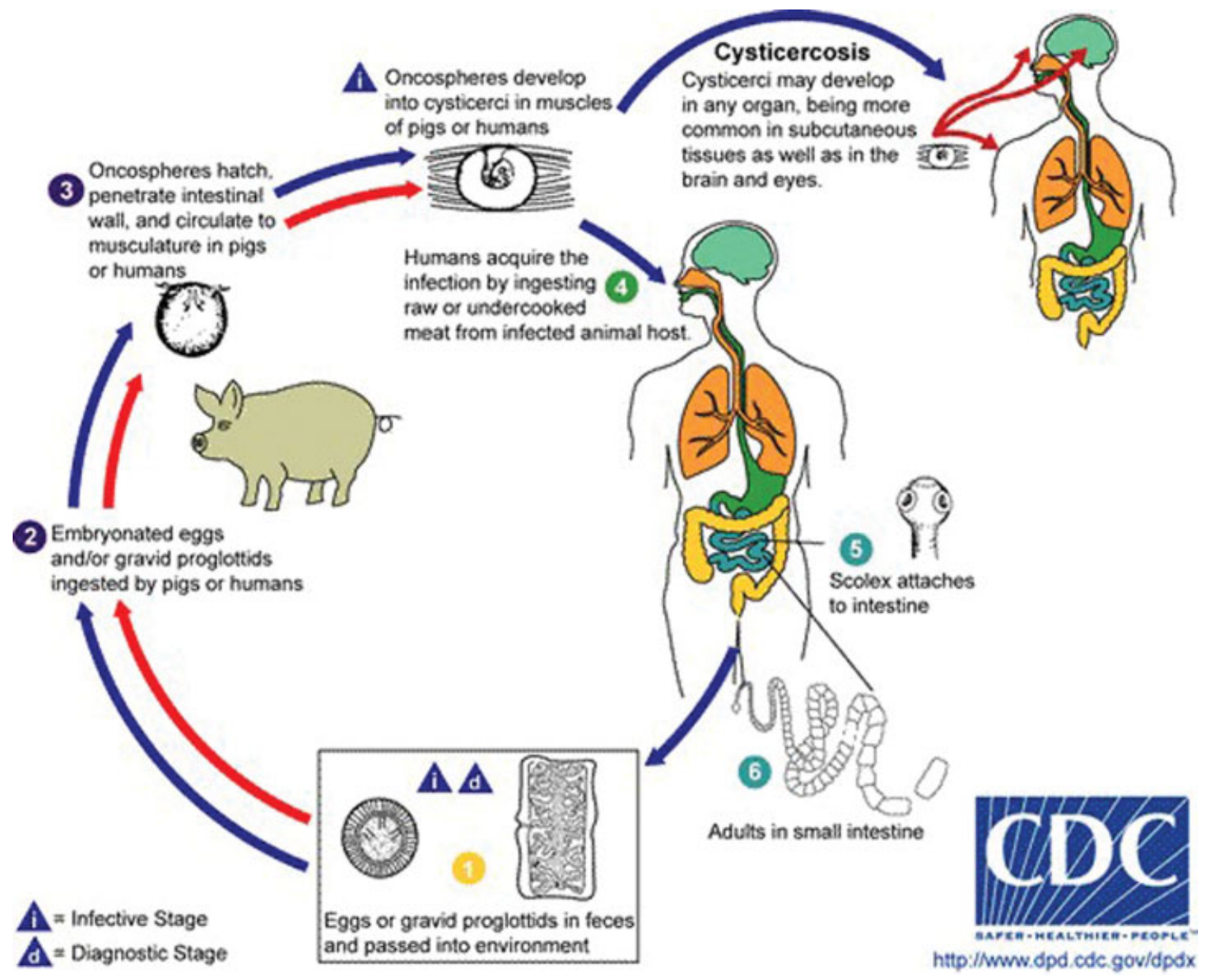

Fig. 5 Life cycle of Taenia solium (www.dpd.cdc.gov/dpdx/HTML/Cysticercosis.htm).

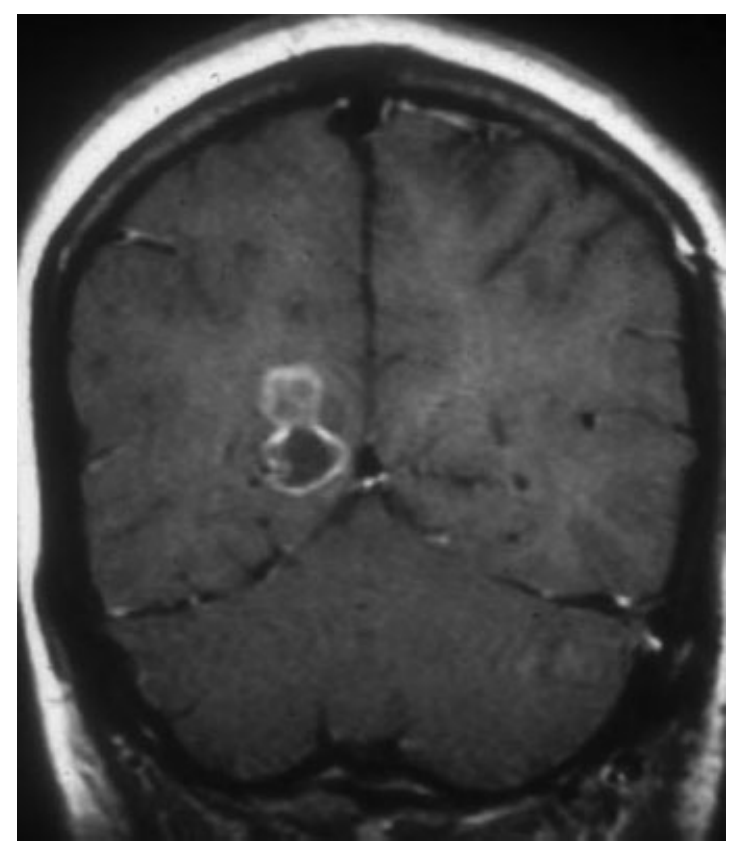

Fig. 6 Magnetic resonance image of brain (coronal T1-weighted) showing a single neurocysticercus in the right hemisphere without significant surrounding edema (http://bestpractice.bmj.com/bestpractice/monograph/358/resources/image/bp/4.html). tools to identify those at high risk of developing seizures and status epilepticus.

Convulsive status epilepticus should be treated in the same way as that due noninfective causes, but depends upon local resources. It is important to keep in mind parainfectious processes that complicate brain infections, including cerebral venous sinus thrombosis and electrolyte abnormalities such as hyponatremia. Nonconvulsive status epilepticus should be excluded in comatose patients, particularly if there is fluctuation in consciousness and/or subtle motor features.

Epilepsy following CNS infections remains a challenge especially in resource-poor settings. The treatment, to some extent, depends upon the natural history of the disease; at the moment, there are no clear predictors of postinfective epilepsy. ${ }^{4}{ }^{11}$ In HSV encephalitis the timing of antiviral medication can reduce the short-term mortality; however, there are few data assessing early antiepileptic medication and the prevention of long-term sequelae. ${ }^{51,52}$ Regardless of the cause, seizure treatment is targeted toward seizure semiology, although many patients with seizures following CNS infections require a combination of antiepileptic medications.

The WHO has produced guidelines specifically targeted at resource-poor settings. ${ }^{53}$ These include the assertion that the diagnosis of epilepsy is clinical and that there should not be 


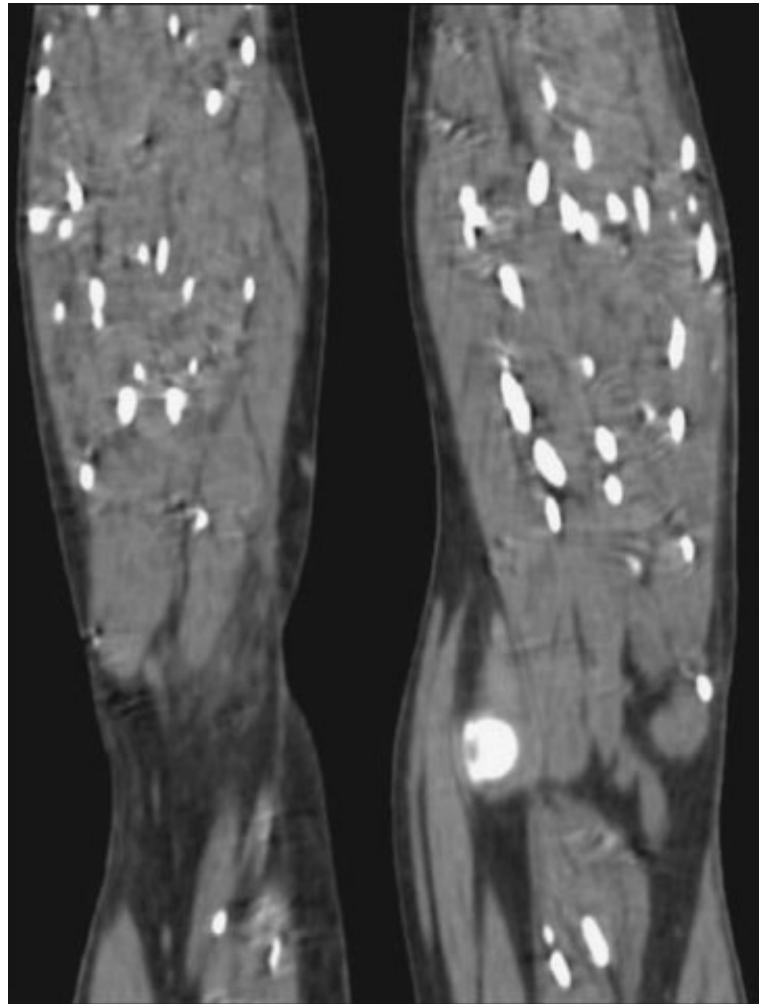

Fig. 7 Plain radiograph of the thighs of a patient with disseminated cysticercosis (www.ijmm.org/article.asp?issn $=0255-0857$; year $=2011$; volume $=29 ;$ issue $=2 ;$ spage $=180$; epage $=183$; aulast $=$ Banu $)$.

an overreliance on neuroimaging and EEG. They also state that nonspecialist health care workers should be trained to recognize and to treat convulsive seizures. Patients should be offered monotherapy with any standard antiepileptic drugwhich can be made available sustainably-and the WHO recommends phenobarbital for patients with generalizedonset and carbamazepine for focal-onset epilepsy. Other firstline medications to consider include lamotrigine, given its efficacy for both focal and generalized seizures, ${ }^{54}$ and levetiracetam, given the low rates of drug interactions and utility in managing convulsive status epilepticus (provided sustainable availability can be achieved). ${ }^{55}$

Charities, such as the Encephalitis Society, can provide support for patients and their family globally, including supplying information. ${ }^{1}$ In resource-poor settings, education programs directed at the patient, their family, and the wider community as to the nature of epilepsy and the basic management of seizures are pivotal in addressing the social stigma that can significantly limit adherence and seizure control, result in injury, and more broadly impact on quality of life..$^{53}$

\section{Conclusion}

Infections of the CNS are an important cause of both acute seizures and later epilepsy. The exact mechanisms underlying this are poorly understood. However, they appear, at least in part, to relate to the pathogen, the degree of cortical involvement, delays in treatment, and the host inflammatory response.
The greatest burden of acute and long-term infection-related seizures occurs in resource-poor settings, where there may be inadequate clinical and research facilities to manage such patients. Nevertheless, education programs may go a long way toward addressing the damaging stigma, and so lead to improved diagnosis, management, and ultimately quality of life.

\section{Acknowledgments \\ BDM received Doctoral Fellowship funding from the Na- tional Institute for Health Research (NIHR) and is a NIHR Academic Clinical Lecturer. TS received support from the NIHR Health Protection Research Unit in Emerging and Zoonotic Infections at Liverpool. BDM is a Trustee for the Encephalitis Society and TS is Chair of their Scientific Advisory Panel.}

\section{References}

1 Solomon T, Michael BD, Smith PE, et al; National Encephalitis Guidelines Development and Stakeholder Groups. Management of suspected viral encephalitis in adults-Association of British Neurologists and British Infection Association National Guidelines. J Infect 2012;64(4):347-373

2 Kneen R, Michael BD, Menson E, et al; National Encephalitis Guidelines Development and Stakeholder Groups. Management of suspected viral encephalitis in children - Association of British Neurologists and British Paediatric Allergy, Immunology and Infection Group national guidelines. J Infect 2012;64(5):449-477

3 Michael BD, Sidhu M, Stoeter D, et al; North West Neurological Infections Network. Acute central nervous system infections in adults-a retrospective cohort study in the NHS North West region. QJM 2010;103(10):749-758

4 Misra UK, Tan CT, Kalita J. Viral encephalitis and epilepsy. Epilepsia 2008;49(Suppl 6):13-18

5 Michael BD, Solomon T. Seizures and encephalitis: clinical features, management, and potential pathophysiologic mechanisms. Epilepsia 2012;53(Suppl 4):63-71

6 Misra UK, Kalita J. Seizures in encephalitis: predictors and outcome. Seizure 2009;18(8):583-587

7 Berg AT, Berkovic SF, Brodie MJ, et al. Revised terminology and concepts for organization of seizures and epilepsies: report of the ILAE Commission on Classification and Terminology, 2005-2009. Epilepsia 2010;51(4):676-685

8 Whitley RJ. Herpes simplex encephalitis: adolescents and adults. Antiviral Res 2006;71(2-3):141-148

9 Widener RW, Whitley RJ. Herpes simplex virus. In: Alex CT, John B, eds. Handbook of Clinical Neurology. Vol 123. Amsterdam, The Netherlands: Elsevier; 2014:251-263

10 Tyler KL. Herpes simplex virus infections of the central nervous system: encephalitis and meningitis, including Mollaret's. Herpes 2004;11(Suppl 2):57A-64A

11 Solomon T, Hart IJ, Beeching NJ. Viral encephalitis: a clinician's guide. Pract Neurol 2007;7(5):288-305

12 Granerod J, Ambrose HE, Davies NW, et al; UK Health Protection Agency (HPA) Aetiology of Encephalitis Study Group. Causes of encephalitis and differences in their clinical presentations in England: a multicentre, population-based prospective study. Lancet Infect Dis 2010;10(12):835-844

13 Höftberger R, Armangue T, Leypoldt F, Graus F, Dalmau J. Clinical neuropathology practice guide 4-2013: post-herpes simplex encephalitis: N-methyl-D aspartate receptor antibodies are part of the problem. Clin Neuropathol 2013;32(4):251-254 
14 De Tiège $\mathrm{X}$, Rozenberg F, Des Portes V, et al. Herpes simplex encephalitis relapses in children: differentiation of two neurologic entities. Neurology 2003;61(2):241-243

15 de Bilbao F, Arsenijevic D, Moll T, et al. In vivo over-expression of interleukin-10 increases resistance to focal brain ischemia in mice. J Neurochem 2009;110(1):12-22

16 Campbell GL, Hills SL, Fischer M, et al. Estimated global incidence of Japanese encephalitis: a systematic review. Bull World Health Organ 2011;89(10):766-774, 774A-774E

17 Griffiths MJ, Turtle L, Solomon T. Japanese encephalitis virus infection. Handb Clin Neurol 2014;123:561-576

18 Impoinvil DE, Solomon T, Schluter WW, et al. The spatial heterogeneity between Japanese encephalitis incidence distribution and environmental variables in Nepal. PLoS ONE 2011;6(7): e22192

19 Solomon T. New vaccines for Japanese encephalitis. Lancet Neurol 2008;7(2):116-118

20 Kumar R, Mathur A, Kumar A, Sharma S, Chakraborty S, Chaturvedi UC. Clinical features \& prognostic indicators of Japanese encephalitis in children in Lucknow (India). Indian J Med Res 1990; 91:321-327

21 Solomon T, Dung NM, Kneen R, et al. Seizures and raised intracranial pressure in Vietnamese patients with Japanese encephalitis. Brain 2002;125(Pt 5):1084-1093

22 Kumar R, Mathur A, Singh KB, et al. Clinical sequelae of Japanese encephalitis in children. Indian J Med Res 1993; 97:9-13

23 Huy BV, Tu HC, Luan TV, Lindqvist R. Early mental and neurological sequelae after Japanese B encephalitis. Southeast Asian J Trop Med Public Health 1994;25(3):549-553

24 Campadelli-Fiume G, Mirandola P, Menotti L. Human herpesvirus 6: An emerging pathogen. Emerg Infect Dis 1999;5(3): 353-366

25 Hall CB, Long CE, Schnabel KC, et al. Human herpesvirus-6 infection in children. A prospective study of complications and reactivation. N Engl J Med 1994;331(7):432-438

26 Epstein LG, Shinnar S, Hesdorffer DC, et al; FEBSTAT study team. Human herpesvirus 6 and 7 in febrile status epilepticus: the FEBSTAT study. Epilepsia 2012;53(9):1481-1488

27 Studahl M, Hagberg L, Rekabdar E, Bergström T. Herpesvirus DNA detection in cerebral spinal fluid: differences in clinical presentation between alpha-, beta-, and gamma-herpesviruses. Scand J Infect Dis 2000;32(3):237-248

$28 \mathrm{Li} \mathrm{J-M}$, Lei D, Peng F, et al. Detection of human herpes virus 6B in patients with mesial temporal lobe epilepsy in West China and the possible association with elevated NF-KB expression. Epilepsy Res 2011;94(1-2):1-9

29 Fotheringham J, Donati D, Akhyani N, et al. Association of human herpesvirus-6B with mesial temporal lobe epilepsy. PLoS Med 2007;4(5):e180

30 Donati D, Akhyani N, Fogdell-Hahn A, et al. Detection of human herpesvirus- 6 in mesial temporal lobe epilepsy surgical brain resections. Neurology 2003;61(10):1405-1411

31 Karatas H, Gurer G, Pinar A, et al. Investigation of HSV-1, HSV-2, CMV, HHV-6 and HHV-8 DNA by real-time PCR in surgical resection materials of epilepsy patients with mesial temporal lobe sclerosis. J Neurol Sci 2008;264(1-2):151-156

32 Kamuyu G, Bottomley C, Mageto J, et al; Study of Epidemiology of Epilepsy in Demographic Sites (SEEDS) group. Exposure to multiple parasites is associated with the prevalence of active convulsive epilepsy in sub-Saharan Africa. PLoS Negl Trop Dis 2014;8(5): e2908

33 Postels DG, Birbeck GL. Cerebral malaria. Handb Clin Neurol 2013; 114:91-102

34 Severe falciparum malaria. World Health organization, communicable diseases cluster. Trans R Soc Trop Med Hyg 2000;94(Suppl 1): S1-S90
35 Lewallen S, Wills BA. Retinal haemorrhage in children with malaria. Lancet 1993;341(8842):442

36 Birbeck GL, Molyneux ME, Kaplan PW, et al. Blantyre Malaria Project Epilepsy Study (BMPES) of neurological outcomes in retinopathy-positive paediatric cerebral malaria survivors: a prospective cohort study. Lancet Neurol 2010;9(12): $1173-1181$

37 Ngoungou EB, Poudiougou B, Dulac O, et al. [Persistent neurological sequelae due to cerebral malaria in a cohort of children from Mali]. Rev Neurol (Paris) 2007;163(5):583-588

38 Opoka RO, Bangirana P, Boivin MJ, John CC, Byarugaba J. Seizure activity and neurological sequelae in Ugandan children who have survived an episode of cerebral malaria. Afr Health Sci 2009;9(2): 75-81

39 Potchen MJ, Birbeck GL, Demarco JK, et al. Neuroimaging findings in children with retinopathy-confirmed cerebral malaria. Eur J Radiol 2010;74(1):262-268

40 Schijns OE, Visser-Vandewalle V, Lemmens EM, Janssen A, Hoogland G. Surgery for temporal lobe epilepsy after cerebral malaria. Seizure 2008;17(8):731-734

41 Ogutu BR, Newton CR, Muchohi SN, et al. Pharmacokinetics and clinical effects of phenytoin and fosphenytoin in children with severe malaria and status epilepticus. Br J Clin Pharmacol 2003; 56(1):112-119

42 Del Brutto OH. Neurocysticercosis. Handb Clin Neurol 2014; 121:1445-1459

43 Ndimubanzi PC, Carabin H, Budke CM, et al. A systematic review of the frequency of neurocyticercosis with a focus on people with epilepsy. PLoS Negl Trop Dis 2010;4(11):e870

44 Medina MT, Aguilar-Estrada RL, Alvarez A, et al. Reduction in rate of epilepsy from neurocysticercosis by community interventions: the Salamá, Honduras study. Epilepsia 2011;52(6): $1177-1185$

45 Sotelo J, Diaz-Olavarrieta C. Neurocysticercosis: changes after 25 years of medical therapy. Arch Med Res 2010;41(1):62-63

46 Carabin H, Ndimubanzi PC, Budke CM, et al. Clinical manifestations associated with neurocysticercosis: a systematic review. PLoS Negl Trop Dis 2011;5(5):e1152

47 Nash TE, Pretell EJ, Lescano AG, et al; Cysticercosis Working Group in Peru. Perilesional brain oedema and seizure activity in patients with calcified neurocysticercosis: a prospective cohort and nested case-control study. Lancet Neurol 2008;7(12):1099-1105

48 Bianchin MM, Velasco TR, Takayanagui OM, Sakamoto AC. Neurocysticercosis, mesial temporal lobe epilepsy, and hippocampal sclerosis: an association largely ignored. Lancet Neurol 2006; 5(1):20-21

49 Pandey S, Rathore C, Michael BD. Antiepileptic drugs for the primary and secondary prevention of seizures in viral encephalitis. Cochrane Database Syst Rev 2014;10:CD010247

50 Crawley J, Waruiru C, Mithwani S, et al. Effect of phenobarbital on seizure frequency and mortality in childhood cerebral malaria: a randomised, controlled intervention study. Lancet 2000; 355(9205):701-706

51 Sköldenberg B, Forsgren M, Alestig K, et al. Acyclovir versus vidarabine in herpes simplex encephalitis. Randomised multicentre study in consecutive Swedish patients. Lancet 1984; 2(8405):707-711

52 Whitley RJ, Alford CA, Hirsch MS, et al. Vidarabine versus acyclovir therapy in herpes simplex encephalitis. N Engl J Med 1986;314(3): 144-149

53 Dua T, Barbui C, Clark N, et al. Evidence-based guidelines for mental, neurological, and substance use disorders in low- and middle-income countries: summary of WHO recommendations. PLoS Med 2011;8(11):e1001122

54 Marson AG, Al-Kharusi AM, Alwaidh M, et al; SANAD Study group. The SANAD study of effectiveness of carbamazepine, gabapentin, lamotrigine, oxcarbazepine, or topiramate for treatment of partial 
244 Infective Causes of Epilepsy Bonello et al.

epilepsy: an unblinded randomised controlled trial. Lancet 2007; 369(9566):1000-1015

55 Trinka E, Marson AG, Van Paesschen W, et al; KOMET Study Group. KOMET: an unblinded, randomised, two parallel-group, stratified trial comparing the effectiveness of levetiracetam with controlled- release carbamazepine and extended-release sodium valproate as monotherapy in patients with newly diagnosed epilepsy. J Neurol Neurosurg Psychiatry 2013;84(10):1138-1147

56 Garcia HH, Del Brutto OH. Infection and inflammation. Handb Clin Neurol 2012;108:601-620 